Conference Proceedings - Short Paper

\title{
Incremental Urbanism: Designing a Resilient Urban Strategy for the Ger Districts of Ulaanbaatar
}

\author{
Joshua Bolchover ${ }^{1 *}$ \\ ${ }^{1}$ Joshua Bolchover, Associate Professor, The University of Hong Kong, Room 729 Knowles Building, \\ Pokfulam, Hong Kong; Tel.: +852 60909847
}

E-Mail: jpbarch@hku.hk

\begin{abstract}
For thousands of years, Mongolians have been living in gers - portable structures made of timber, felt and canvas. Throughout the history of Mongolia's capital city, Ulaanbaatar, the ger has remained the predominant dwelling for new migrants, a resilient typology indifferent to technological progress or to the radical political and economic shifts that took place after the 1990 democratic revolution. However, this paper demonstrates that the engineered resilience of the ger as a dwelling typology has led to unsustainable urban development. By analysing the process of transformation of ger districts, the objective is to propose a framework for incremental change that advocates a position for social-ecological resilience. The essay will report on the impact of the construction of a series of architectural prototypes including an affordable housing unit and a community innovation hub that have been developed as part of the incremental plan. The strategy is a unique example of how urban resilience can be addressed through interventions that tackle urgent issues yet can allow for future adaptation and transformation.
\end{abstract}

Keywords: Incremental urbanism; ger districts; informal settlements; affordable housing. 


\section{Unsustainable development in Ulaanbaatar}

The ger is a resilient, engineered artefact that has evolved in direct correlation to the demands of nomadic life. It is designed for portability, can be easily disassembled and reassembled without any mechanical fixings, and all of its component parts are prefabricated and can be bought at everyday markets. A ger costs between 600USD-1000USD, making it the most economical form of housing in the city. Its ease of transportation, affordability and reproducibility in large numbers have been one of the main contributing factors to the speed and extent of the urbanization process in the city of Ulaanbaatar.

Figure 1. Ger districts in Ulaanbaatar, Mongolia

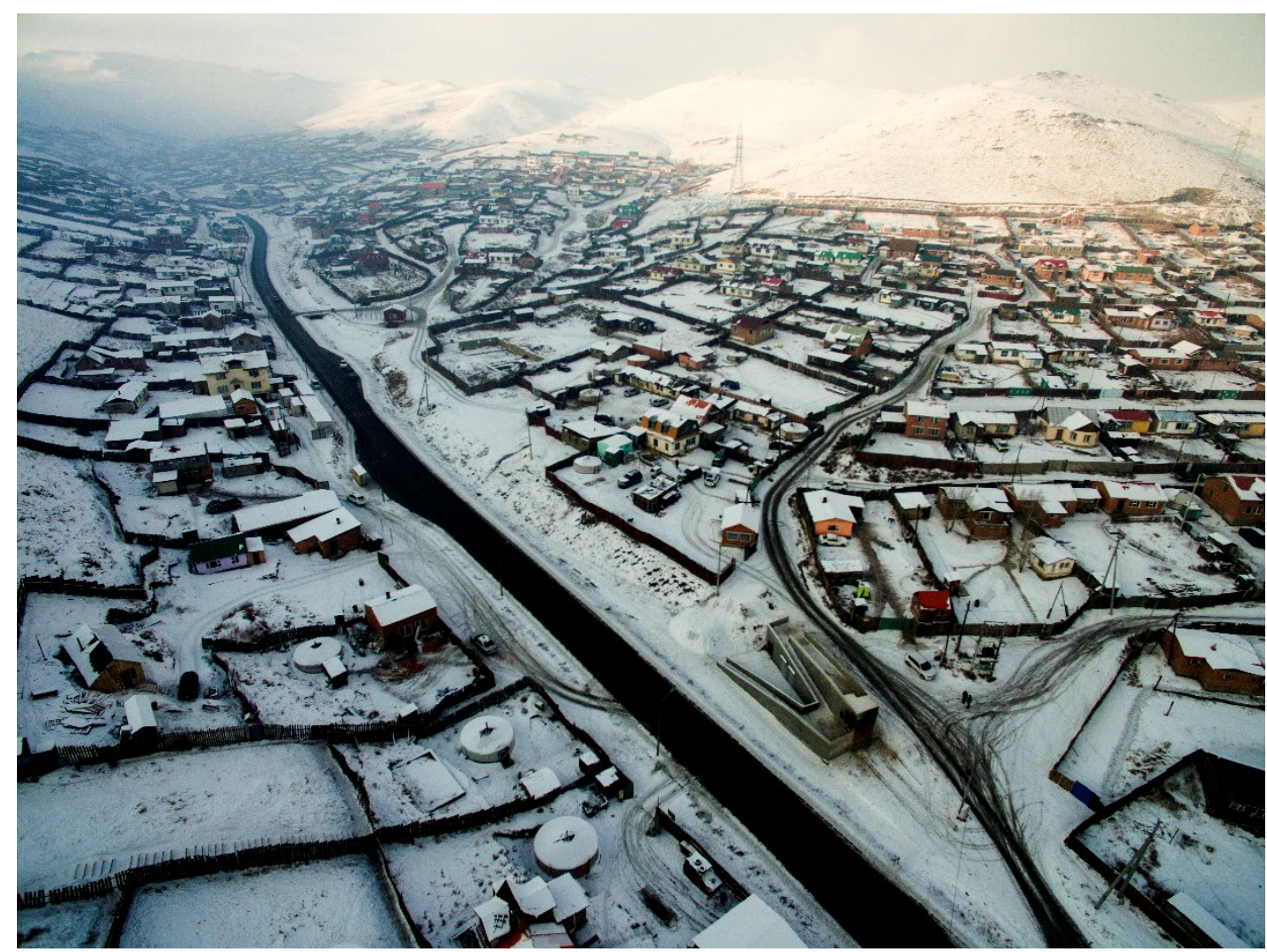

Rural Urban Framework

The draw of the city in terms of access to healthcare, jobs, and educational opportunities, was compounded in 2002 by Mongolia's land law which allowed each Mongolian citizen the right to claim and own a land plot of $700 \mathrm{~m}^{2}$. This accelerated the migration of rural nomads to the city. The population of the city has increased by $230 \%$ in the last 20 years (National Statistical Office, Mongolia, 2013) resulting in the creation of sprawling districts with no basic infrastructure that nevertheless house over $70 \%$ of the city's population. The cold winters mean that each ger district household uses around 3.8-5 tonnes of unrefined coal as their main heating source, contributing to toxic air pollution reaching levels reported to be 133 times higher than the World Health Organization (WHO) guideline. (National Center for Public Health and UNICEF, 2018). Water is collected from water kiosks with families making at least 8 trips per week, collecting approximately 500 litres of water; $95 \%$ have access only to pit latrines, (The World Bank, 2017). As the population of migrants grows by 35,000 each year, the urban risks 
associated with this form of settlement are becoming increasingly threatening, particularly with respect to sanitation, freshwater supply and air quality.

Figure 2. Households in the ger districts burning coal during winter.

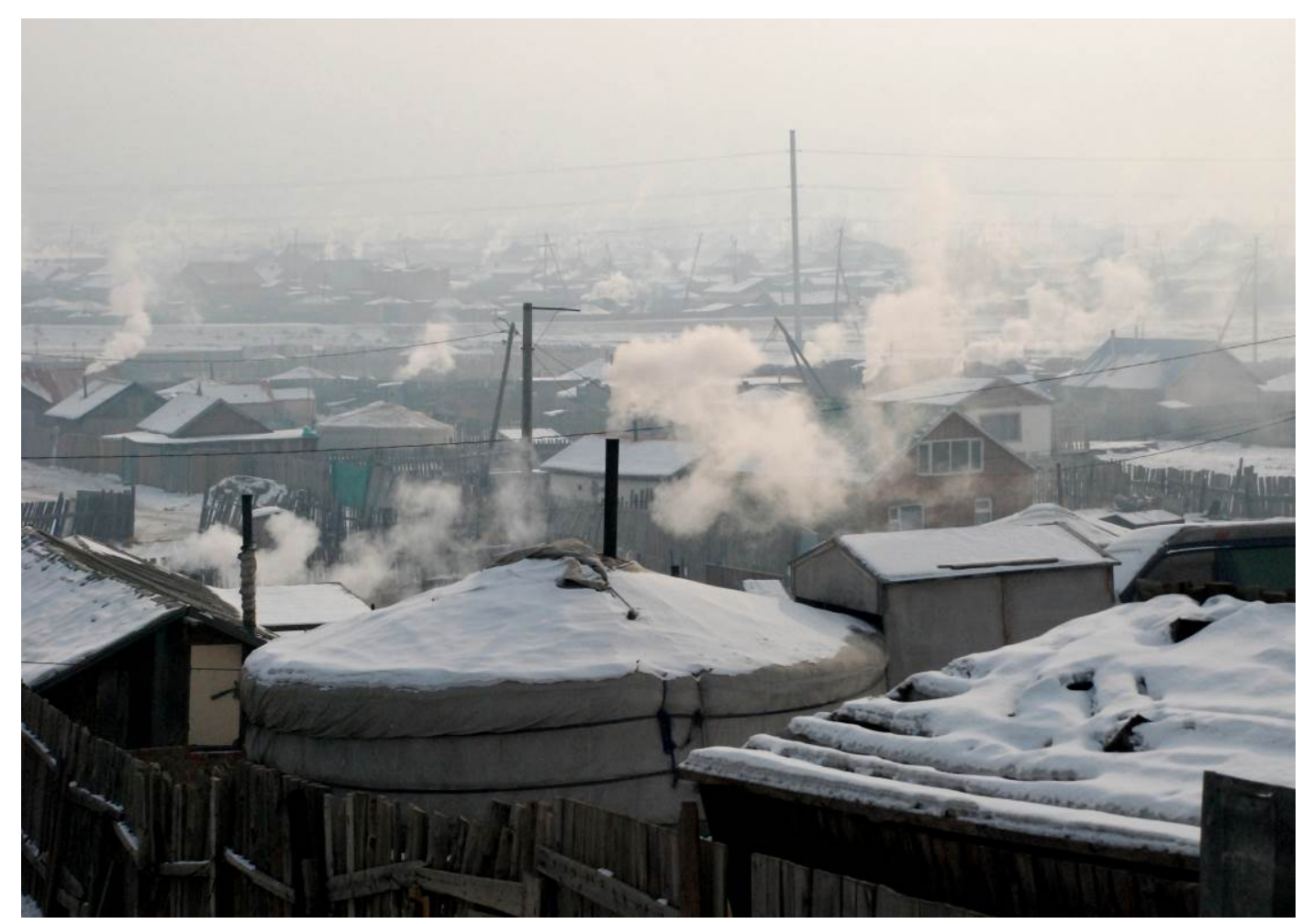

Rural Urban Framework

Figure 3. Ger district residents collecting water at a water kiosk.

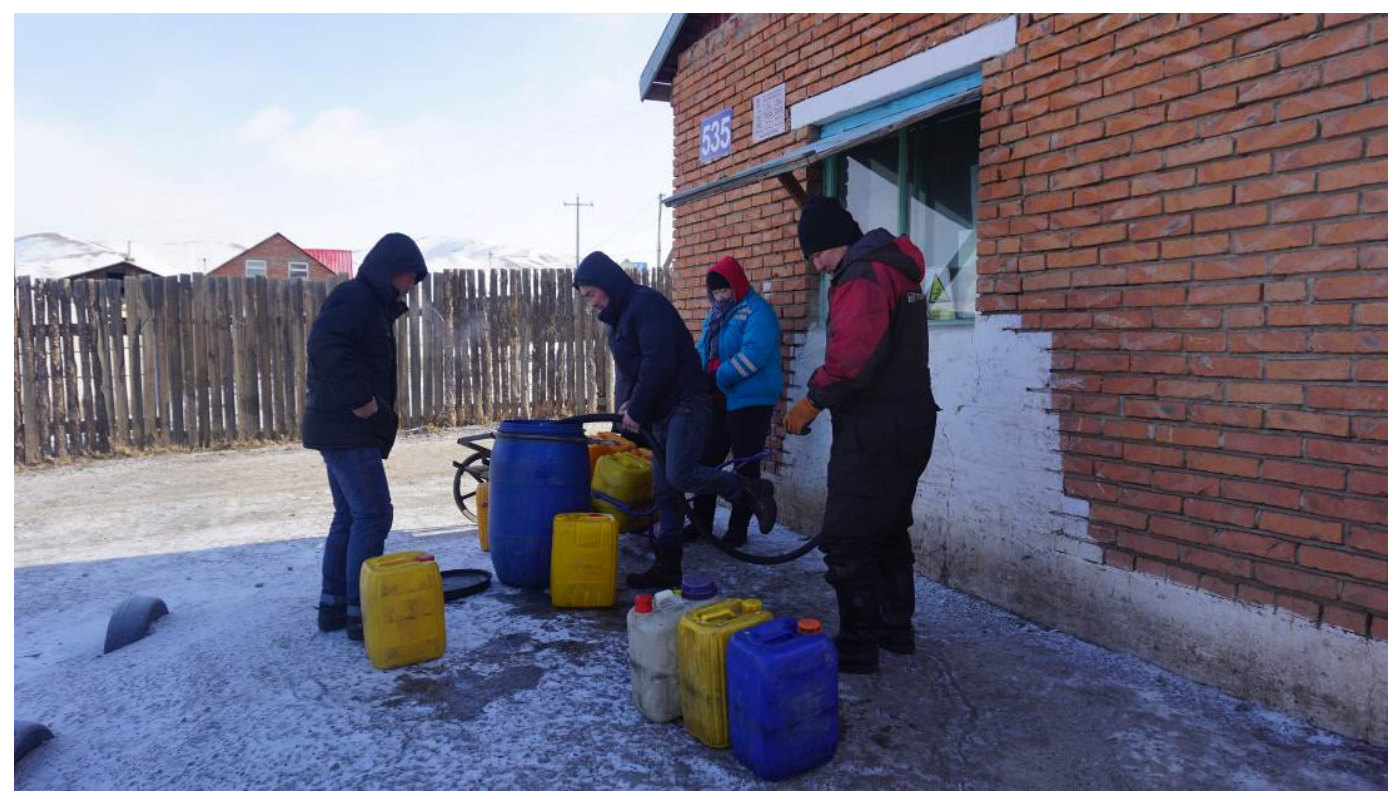

Rural Urban Framework 
Although designed for the open steppe, once sedentary in the city, the ger becomes rooted and enclosed by a fence demarcating the plot boundary. Over time, some residents have modified their ger adding simple wooden thresholds to prevent heat loss or building permanent concrete foundations to limit the cold from the ground. Over 65\% (Asia Pacific Investment Partners, 2017) of families build a simple house or baishin, yet based on our fieldwork, many retain the organization of the ger, tending towards shared spaces rather than separate room divisions. Most still lack internal toilets and showers, are ineffectively thermally insulated and are still reliant on coal, with over $85 \%$ of ger district residents using wood or coal-burning stoves for heating (The World Bank, 2010). Overtime, more established districts densify through subdivision, becoming more consolidated urban grids, while the newer districts continue to expand into virgin territory. Despite subdivision, the predominant housing typology is a detached single family house and so density is low, ranging between 2.1 structures/plot (plot size averaging $453 \mathrm{~m}^{2}$ in the older districts to 1.6 structures/ plot (plot size averaging $734 \mathrm{~m}^{2}$ in the outer, newest districts. Apart from basic infrastructure, these districts also lack civic infrastructure in the form of kindergartens, medical facilities, and community spaces. For example: in Songino Khairkhan-31, there are no schools, only 2 kindergartens and no community spaces for the 3,000 households in the district. This form of urban growth is clearly unsustainable as each new resident contributes to worsening pollution, toxic waste and pressures on water supply.

Because the majority of residents own their land, large scale development requires huge investments towards compensation and infrastructure. Current plans are reliant on loans from the Asian Development Bank that will ultimately have to be paid back, stretching the stabilization of Mongolia's already volatile and uncertain economy which is reported to have \$2bn in external sovereign debt, (Koyanagi, Nikkei Asian Review, February 2017). The Ger Areas Development Investment Program (GADIP) promotes a more sustainable urban model of 6-story townhouses with shared greenhouses supported by infrastructural connection, however, it is reliant on landowners being compensated for their land in the form of $35 \mathrm{~m}^{2}$ apartments and the involvement of private sector developers as delivery agents. Even if realised, these plans will not impact the fringe districts of the city, where new migrants settle each year.

\section{Framework for incremental change}

The strategy is to create a mechanism for residents to maintain landownership and develop their plots themselves. It promotes incremental development in response to our observations in the context, acting as an enabling tool to kick-start a process of change that links top down financial initiatives to local people.

The Green Climate Fund approved programmes proposed by different local financial institutions in the form of bank loans in October 2018. Local banks can create mortgage products to access these better loan rates, $10-12 \%$ compared to $18 \%$, (meeting with Xac Bank $23^{\text {rd }}$ Oct 2018), based on delivering housing that meets the criteria of a $20 \%$ reduction in $\mathrm{CO}_{2}$ emissions. The onus is on construction companies to create housing products that demonstrate that these criteria can be achieved. The mortgage is with individual residents who will agree on a product, then the money will go to the contractor to build the house. However, there are currently only two products available on the market eligible for these low interest loans. Our proposal is to unlock this funding by creating a development toolkit - a series of different products serving a range of incomes and housing types that meet the criteria-thereby enabling residents to incrementally develop their own plots. 
The mechanism is to set up a Ger District Development Corporation comprised of an architect (Rural Urban Framework at the University of Hong Kong), a community advisor, a financial real estate expert, a lawyer and a contractor. It will act as a delivery agent, making sure the buildings that are constructed comply with improved environmental performance. The difference in our model is that it promotes densification, diversifies the housing typologies available on the market and provides income streams that can be used for neighborhood investment. The scenario for a one plot densification scheme is as follows. The land owner takes a loan to build infrastructure consisting of a septic tank and water tank with added capacity for two more households, together with an energy efficient house. The access to infrastructure on his plot means he can attract new residents to lease the land. These residents take a loan to pay for the rights of land use and to build a house, again selected from the toolbox meeting the $20 \%$ reduction criteria. Income generated from the rent is used to pay back the initial loan, however a percentage is retained to contribute to a neighborhood improvement fund. This fund is managed by the residents and used to invest in communal benefits such as landscaping, greenhouses, car parking or any necessary repairs to collective infrastructure. Additional income created through rentals can allow existing residents to further invest or co-invest in more housing or in profit-making ventures such as shops, car parking or workspaces. Critically, unlike other development models, land ownership resides with the residents themselves. In a city whereby $97.8 \%$ land is owner occupied by a population with an average monthly income of around \$80USD (The World Bank, 2017), the mechanism initializes a process to increase the value of their land. 
Figure 4. One plot densification scenario.

STAGE 0

Existing condition

Single family on a plot without infrastructure

Carbon Emissions:

No of Families:

Infrastructure:
$100 \%$

No
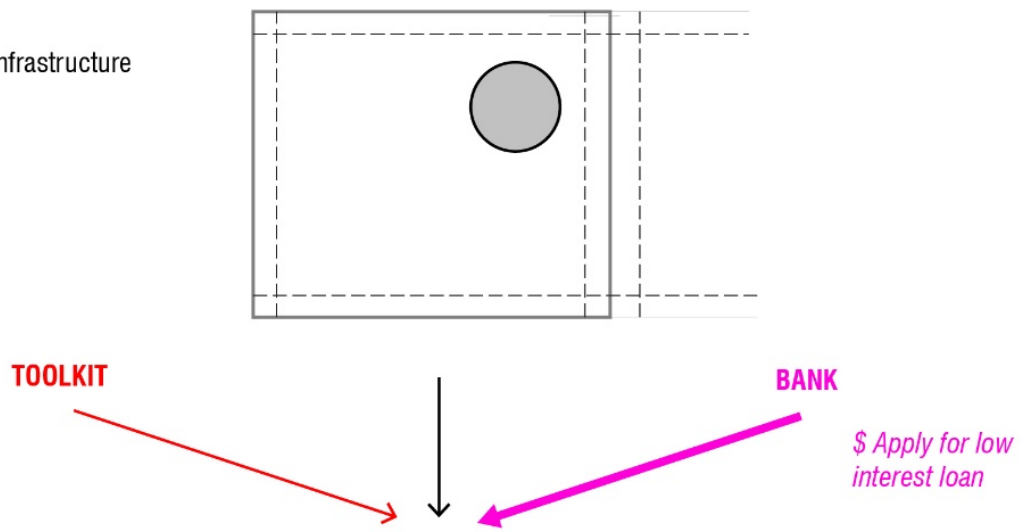

STAGE 1 Owner takes loan to build infrastructure with added capacity and an energy efficient house.

Carbon Emissions: $\quad>20 \%$ reduction

No of Families: $\quad 1$

Infrastructure: Yes
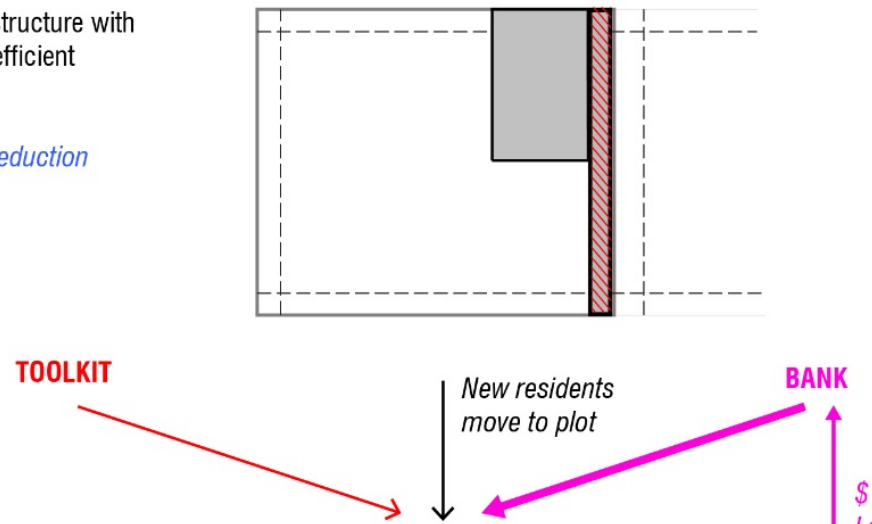

STAGE 2 New residents move to plot and take loan to pay for right to lof land use and to build a house

Carbon Emissions: $\quad>20 \%$ reduction

No of Families: $\quad 2+$

Infrastructure: Yes

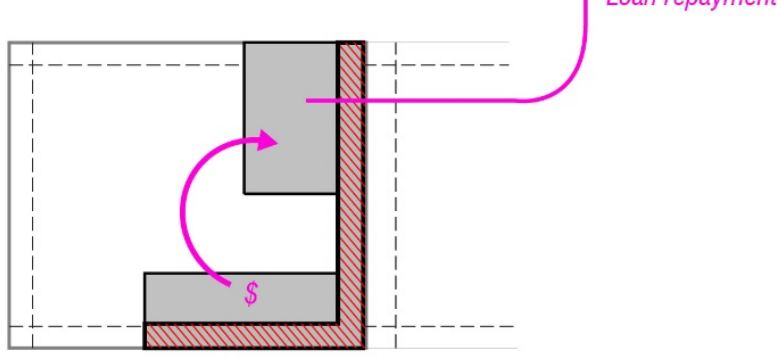

TOOLKIT

STAGE 3 Income from rent used to invest in new programmes and infrastructure such as shops and greenhouses to generate different income streams

Carbon Emissions:

$>20 \%$ reduction

No of Families:

$4+$

Infrastructure:

Yes

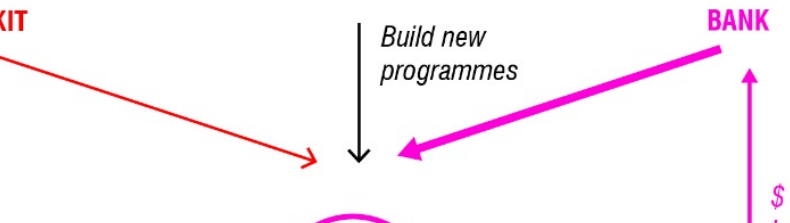

Loan repayment

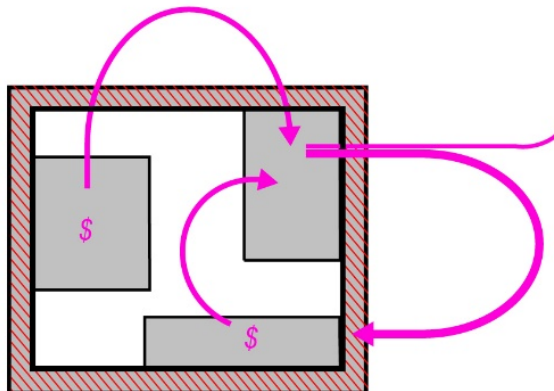

$\$$

Maintenence and Improvements 


\section{Impact of pilot projects}

The first pilot product that we have developed as part of the tool-kit is an affordable housing unit entitled The Ger Plug-In. As demonstrated, the ger is responsible for the unsustainable urban patterns emerging in the city, and so it has to evolve and adapt to its new sedentary context. The Ger Plug-In fuses the traditional structure of a ger with typical timber house construction. A new truss suspends the ger from above, allowing the centrally placed columns to be removed and the stove to relocate within the thermal mass of a brick wall. This liberates the ger as a free-space providing the family with more options for how they wish to live. The project improves the environmental performance of the household testing low-tech, off-grid systems providing a septic treatment system and WC; water tank and shower; underfloor heating; an electric boiler and a passive solar trombe wall made of black PVC pipes filled with sand. Together these systems act to provide much needed basic infrastructure to the ger and reduce coal consumption. After a one year testing period, we can note that: from October to December 2017, when the external temperature was between $-9.9^{\circ} \mathrm{C}$ and $-19.8^{\circ} \mathrm{C}$, the Plug-In was $2.48^{\circ} \mathrm{C}$ warmer than a traditional ger. The average daily temperature fluctuation in the Plug-In was $4.1^{\circ} \mathrm{C}$ compared to $10.2^{\circ} \mathrm{C}$ in a traditional ger. The thermal stability of the Plug-In, due to its additional thermal mass, meant that during a period of inoccupation when the temperatures ranged from $-12.5^{\circ} \mathrm{C}$ to $-23.4^{\circ} \mathrm{C}$, it took five days for all parts of the interior to reach negative temperatures. During the winter, the residents used an estimated 93\% less coal than their previous year living in a ger, an estimated 0.266 tonnes compared to an average of 3.8tonnes, a coal reduction of 3.534 tonnes. If each of the 104,000 ger households (Mongolia Real Estate Report 2017, Asia Pacific Investment Partners) was replaced by a Plug-In this would result in an estimated saving of 27,664 tonnes of coal per year.

Figure 5. The Ger Plug-in

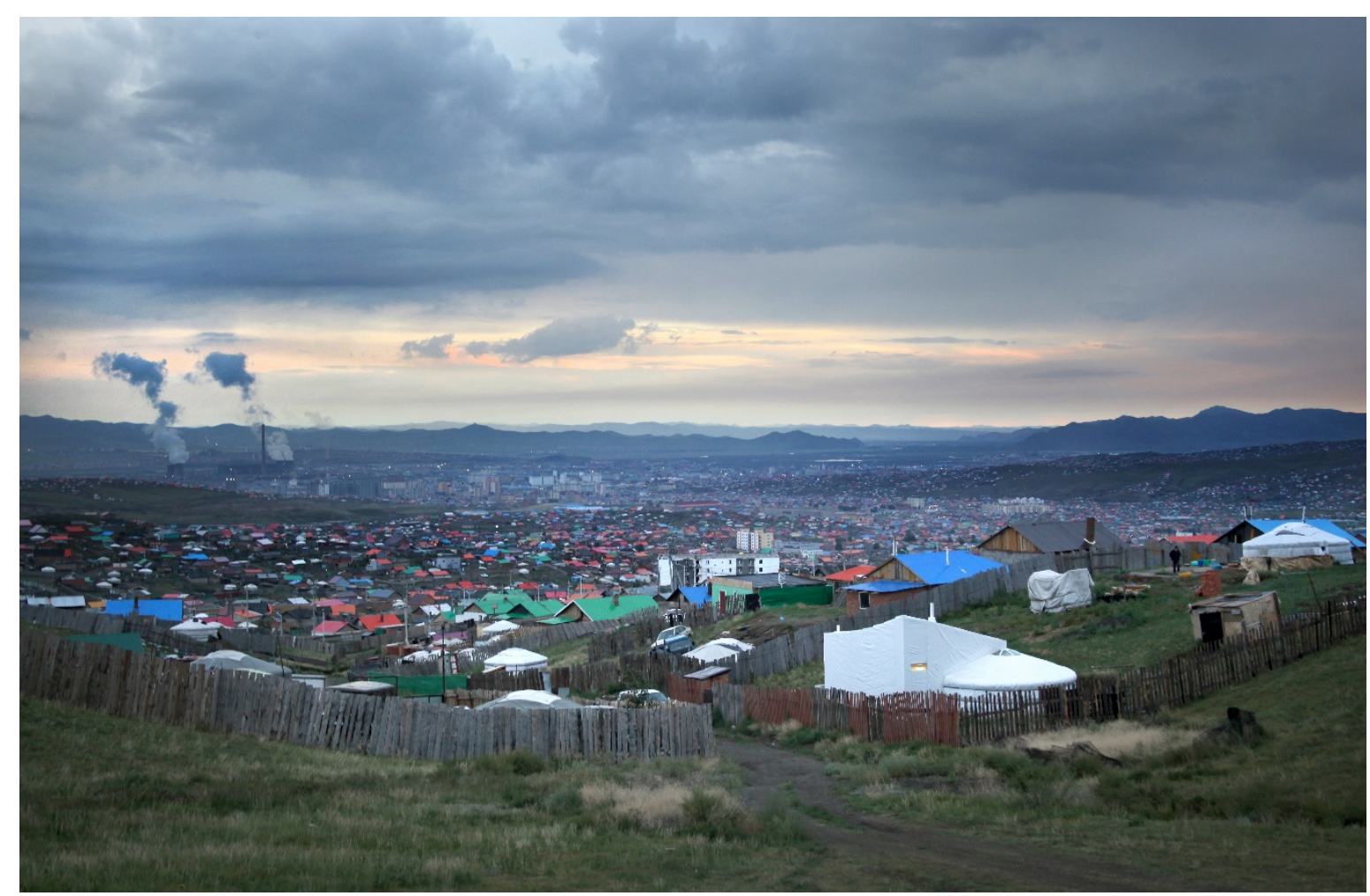

Rural Urban Framework 
However, housing is not the only issue: the Ger districts desperately lack civic and community infrastructure. The Ger Innovation Hub is designed as a layered structure, comprised of an inner room that is wrapped in an outer layer of polycarbonate that creates a buffer space that traps radiant heat in the winter. The energy models indicate that during a winter's day, with an outside temperature of $-20^{\circ} \mathrm{C}$ this buffer zone would be at $-1.4^{\circ} \mathrm{C}$, therefore the inner zone would only have to heated to $+15^{\circ} \mathrm{C}$ rather than make up the differential of $33.6^{\circ} \mathrm{C}$, significantly lowering energy consumption. The building will provide a space for all sections of the community supporting a crèche, youth facilities, vocational training and a place for screenings and performances. Over time, it can include small cooperative enterprises and demonstrate how an entire plot can be used to engage community needs and serve as a model to reduce carbon emissions.

Figure 6. The Ger Innovation Hub

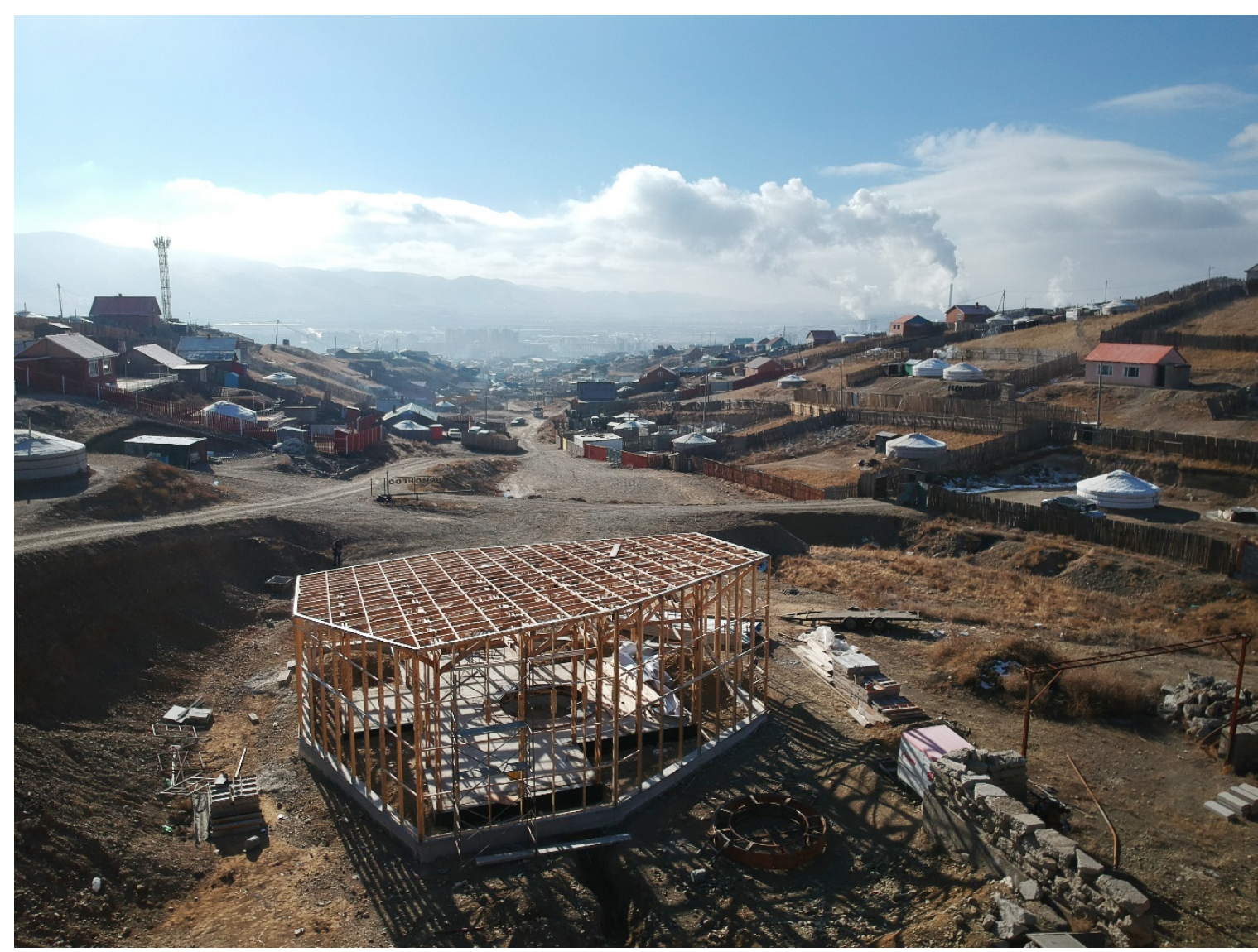

Rural Urban Framework 


\section{Incremental urbanism as social-ecological resilience}

The two projects are examples from the tool-kit for incremental development. The Ger-Plug-In demonstrates how the resilience of the ger can be adapted and transformed, opening up the possibility for sustainable development. The aim is to "seed" a transformation process that can lead to the creation of off-grid infrastructural networks. Using the mechanism of the Green Climate Funds, if the Plug-In can be accepted as a viable product eligible for low interest rate mortgages, it could allow thousands of households' access to improved infrastructure with lower carbon emissions. However, the intention is not to rubber-stamp this product as a singular solution but to provide mechanisms to diversify housing typologies and increase density on each plot. The only mechanism to improve the overall sustainability of the city is to provide an alternative to sprawl and the outward expansion of the city. If the land-law remains, and people are reluctant to give up their land, the city has to be able to densify. To densify, the land has to become more valuable in order to stimulate development. Land value can be increased by providing shared access to infrastructure, incentivizing residents to leverage development for themselves. In this way, by opening up access to low interest loans we can incrementally transform the ger districts into a viable low carbon community while still maintain land ownership with the residents themselves. The long term objective is to build capacity for a healthier population with more money in their pocket, offering Mongolia's young, upwardly mobile citizens a more sustainable urban future.

\section{Acknowledgments}

The research project "Incremental Urbanism: Ulaanbaatar's Ger Settlements" is funded by the Research Grants Council of the Hong Kong Special Administrative Region. The Ger Plug-In construction was funded by the Lorinet Foundation.

\section{Conflict of Interest}

"The authors declare no conflict of interest"

\section{No references for the short papers but hyperlinks within the text}

(C) 2018 by the authors; licensee MDPI and IFoU, This article is an open access article distributed under the terms and conditions of the Creative Commons Attribution license. 